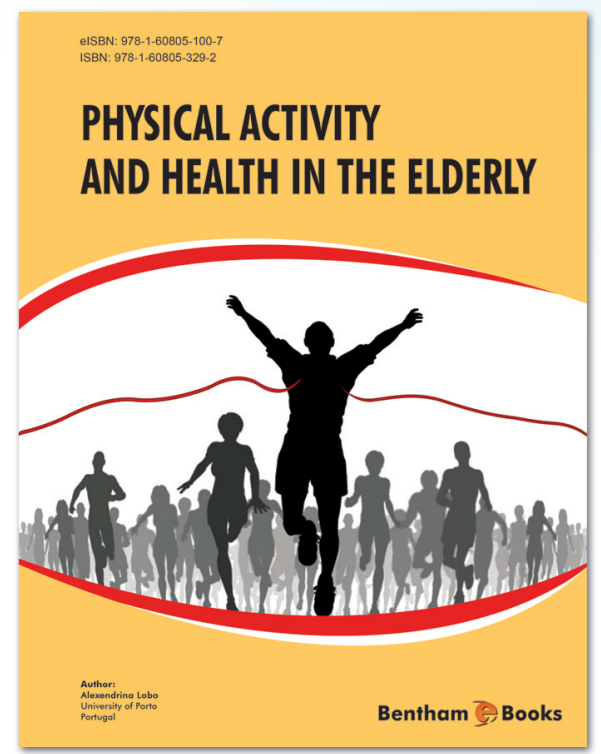

Single user / Non-Library usage

US\$ 21.00

Print-On-Demand (P.O.D)

US\$ 42.00

Author:

Alexendrina Lobo

Portugal

Indexed in: Scopus

elSBN: 978-1-60805-100-7

\title{
Physical Activity and Health in the Elderly
}

\section{Ww.ehooks.henthamseience.com/hook/9781608051007}

\section{About the eBook}

Engagement in health promoting behavior in the domains of physical activity, healthy dietary practice and stress management are considered useful strategies to enhance functional capacity among elderly people. This Ebook goes a long way in promoting healthy values by providing people with information and tools to help meet the challenges of promoting physical activity for older adults in this dynamic 21 st century we live in.

\section{Contents}

- Physical Activity

- Physical Activity Programs for Elders

- Physical Performance

- Physical Activity and Life Expectance

- Organization of Sport Animation

- Falls in the Elderly

- Rehabilitation in the Elderly

For Sales Advertising Inquiries: Contact: marketing@benthamscience.org 